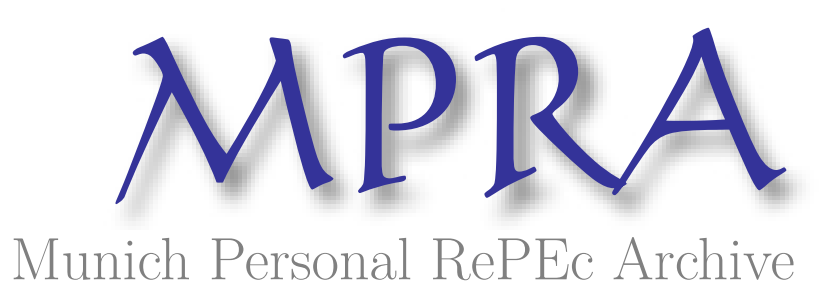

\title{
A comparison of screening mechanisms for identifying potentially anticompetitive accountable care organizations
}

Pelnar, Gregory

29 July 2011

Online at https://mpra.ub.uni-muenchen.de/32485/

MPRA Paper No. 32485, posted 30 Jul 2011 05:27 UTC 
A Comparison of Screening Mechanisms for Identifying Potentially Anticompetitive Accountable Care Organizations

Gregory J. Pelnar

Compass Lexecon

Draft: July 29, 2011 
Abstract: The FTC and D0J's Proposed Statement of Antitrust Enforcement Policy Regarding Accountable Care Organizations Participating in the Medicare Shared Savings Program explains how the antitrust agencies will screen accountable care organizations (ACOs) to identify ones that are potentially anticompetitive and therefore require further review. In contrast to the antitrust screens the agencies have set forth in earlier Statements or Guidelines which are based on market shares in relevant markets, the Proposed Statement introduces a screen based on market shares in Primary Service Areas (PSAs). By examining several numerical examples, the proposed ACO screen is compared to some alternatives, including the review thresholds set forth in the 2010 Horizontal Merger Guidelines. The results indicate that the proposed ACO screen produces results qualitatively similar to other screens in some instances, but can be more stringent or more lax in others. It is therefore at best premature to conclude that PSAs are a useful tool for screening out potentially anticompetitive ACOs. 
Be careful what you ask for. That is a warning that health care providers may have, in retrospect, wished they had heeded. They sought clarity - preferably blank check antitrust immunity - from the Federal Trade Commission (FTC) and the U.S. Department of Justice Antitrust Division (DOJ) in setting up provider networks called accountable care organizations (ACOs) to participate in Medicare's Shared Saving Program. Instead, they got the FTC and D0J's Proposed Statement of Antitrust Enforcement Policy Regarding Accountable Care Organizations Participating in the Medicare Shared Savings Program ("Proposed Statement"). ${ }^{1}$

The antitrust agencies could have simply pointed to pre-existing guidance: their 1996 Statements of Antitrust Enforcement Policy in Health Care ${ }^{2}$, their 2000 Antitrust Guidelines for Collaborations Among Competitors ${ }^{3}$, and their 2010 Horizontal Merger Guidelines. ${ }^{4}$ They could have simply re-iterated the need for financial or clinical integration, the ancillarity of joint negotiations with payers, the need for pro-competitive benefits, the antitrust safety zones based on market share in the relevant market, and so on. Much of the pre-existing guidance was based on years of careful economic thinking about the issue at hand.

Providers argued there was too much ambiguity as to how the antitrust laws would be applied to the ACOs formed in response to provisions of the 2010 Affordable Care Act. Some providers went so far as to assert that the antitrust laws stood in the way of ACO formation and frustrated the objective of health care reform. They wanted the antitrust agencies to stand aside; any ACO approved by the Centers for Medicare and Medicaid Services (CMS) to participate in its Shared Savings Program should not be challenged by the antitrust agencies.

The FTC and DOJ, to their credit, were concerned. They were worried about ACOs that could be little more than cartels. They were worried about the creation of market power via ACO formation. And they were worried about antitrust conspiracies among ACO members concerning their non-ACO activities. Their answer was the Proposed Statement.

At least for the purposes of screening ACOs to identify those that warrant closer scrutiny by the antitrust authorities, out went the delineation of the relevant market based on sound economic reasoning, such as the availability of substitutes and the hypothetical monopolist test. ${ }^{5}$ In came the delineation of 'primary service areas' (PSAs) based on an algorithm that ignores virtually everything that economic theory suggests is important for an analysis of market power.

${ }^{1}$ FTC \& DOJ, Proposed Statement of Antitrust Enforcement Policy Regarding Accountable Care Organizations Participating in the Medicare Shared Savings Program, Federal Register, vol. 76, no. 75 (April 19, 2011), pp. 21894-902. 2 DOJ \& FTC, Statements of Antitrust Enforcement Policy in Health Care (August 1996).

3 FTC \& DOJ, Antitrust Guidelines for Collaborations Among Competitors (April 2000). 4 DOJ \& FTC, Horizontal Merger Guidelines (August 19, 2010).

5 The Proposed Guidelines explain the screening mechanism to be used to identify ACOs that warrant closer antitrust scrutiny, but do not explain how the antitrust agencies will conduct their review of the ACOs needing further scrutiny. 
The purpose of this study is to explore how the screening of potentially anticompetitive ACOs under the Proposed Statement's PSA Approach compares with the results obtained by applying the screens set forth in the antitrust agencies' earlier guidance.

\section{Comparison of ACO Antitrust Treatment as Set Forth in the Proposed Statement and under the Statements of Antitrust Enforcement Policy in Health Care and the Antitrust Guidelines for Collaborations Among Competitors}

Before the 2011 Proposed Statement, health care providers wondering where the antitrust safety zone is could consult the FTC and DOJ's 2000 Antitrust Guidelines for Collaborations Among Competitors ("Collaborations") and find that, "[a]bsent extraordinary circumstances, the Agencies do not challenge a competitor collaboration when the market shares of the collaboration and its participants collectively account for no more than twenty percent of each relevant market in which competition may be affected." 6

They could also go back further and consult the 1996 Statements of Antitrust Enforcement Policy in Health Care ("1996 Statements") and find that the antitrust agencies "will not challenge, absent extraordinary circumstances, an exclusive physician network joint venture whose physician participants share substantial financial risk and constitute 20 percent or less of the physicians in each physician specialty with active hospital staff privileges who practice in the relevant geographic market" and that "[g]enerally, relevant geographic markets for the delivery of physician services are local." 7 They would also find that the agencies "will not challenge, absent extraordinary circumstances, a non-exclusive physician network joint venture whose physician participants share substantial financial risk and constitute 30 percent or less of the physicians in each physician specialty with active hospital staff privileges who practice in the relevant geographic market." ${ }^{8}$ While they would find no antitrust safety zone for multiprovider networks comprised of different types of health care providers, such as physician-hospital organizations, they would find an explanation of how to define the relevant market to carry out a rule of reason analysis.

Now they learn that, "[f]or an ACO to fall within the safety zone, independent ACO participants (e.g., physician group practices) that provide the same service (a "common service") must have a combined share of 30 percent or less of each common service in each participant's PSA, wherever two or more ACO participants provide that service to patients from that PSA", where the PSA is defined as "the lowest number of contiguous postal zip codes from which the [ACO participant] draws at least 75 percent of its [patients]" for that service. ${ }^{9}$

${ }^{6}$ Collaborations, supra note 3, p. 26 (emphasis added).

${ }^{7} 1996$ Statements, supra note 2, pp. 64-65 (emphasis added).

8 Id., p. 65 (emphasis added).

${ }_{9}^{9}$ Proposed Statement, supra note 1, p. 21897. 
The familiar (albeit often contentious) "relevant market" has been replaced by the "primary service area", which as the Proposed Statement explains "does not necessarily constitute a relevant antitrust geographic market" but "nonetheless provides a useful tool for evaluating potential competitive effects", and by "an ACO's shares of services (i.e., physician specialties, major diagnostic categories ("MDCs") for inpatient facilities, and outpatient categories for outpatient facilities) in the relevant PSAs" even though "these services do not necessarily constitute relevant antitrust product markets" but "nonetheless provide a useful tool for evaluating potential competitive effects." ${ }^{10}$ In other words, in place of an antitrust safety zone market share threshold based on the familiar 'relevant product market' and 'relevant geographic market' there was now one based on health care codes that do not necessarily delineate relevant product markets and geographic areas that do not necessarily delineate relevant geographic markets.

The virtue of the Proposed Statement's safety zone is that, given the same data on where each provider draws patients for each service, everyone should get the same answer. This is in marked contrast to questions about relevant markets, where even the most reasonable of people may disagree. Ambiguity as to where economic logic dictates the lines of the relevant market should be drawn has been replaced with precision as to where the lines should be drawn irrespective of economic logic.

But is the safety zone set forth in the Proposed Statement broader or narrower than the safety zones set forth in earlier guidance? First consider the 1996 Statements. The safety zones have three basic components: (1) a financial integration requirement, and (2) a market share threshold that is a function of (3) whether the arrangement is exclusive or non-exclusive. The financial integration requirement may be satisfied by the very fact that the ACO will participate in the Medicare Shared Savings Program, thereby giving each of the ACO's members a financial interest in the ACO's success. The Proposed Statements also require certain types of ACO participants, such as hospitals, to only do so on a non-exclusive basis, but otherwise does not condition the market share threshold on whether ACO participation is on an exclusive or non-exclusive basis. The Proposed Statement puts the safety zone threshold at 30\% PSA market share, while the 1996 Statements put it at a market share of either $20 \%$ or $30 \%$ of the relevant market. One may be tempted to thus conclude that the safety zones specified in the two documents are not so different.

Does the Proposed Statement set forth a safety zone which is more, less, or equally strict as the Collaborations? If an ACO's PSA is its relevant geographic market and assuming the service in question constitutes the relevant product market, then the former's 30\% threshold exceeds the latter's $20 \%$ threshold, so that the Proposed Statement sets forth a broader safety zone than the Collaborations. However, what if we retain the assumption that the service in question is the relevant product market and now assume an ACO's PSA is not necessarily its relevant geographic market? Once again, one may be tempted to conclude that the

${ }^{10} I d .$, pp. 21896-97. 
Proposed Statement sets forth a safety zone that is at least as broad as that set forth in the Collaborations.

In fact, neither conclusion is warranted, as some simple examples illustrate.

\begin{tabular}{|c|c|c|c|c|}
\hline \multirow[t]{2}{*}{ Example 1: } & \multicolumn{4}{|c|}{ Zip code } \\
\hline & 1 & 2 & 3 & 4 \\
\hline Provider J's Medicare revenue for service $s$ (dollars) & 40 & 35 & 15 & 10 \\
\hline Medicare revenue for service $s$ to all providers (dollars) & 100 & 100 & 100 & 100 \\
\hline \multicolumn{5}{|l|}{ Provider J's PSA for service $s$ consists of zip codes $1 \& 2.11$} \\
\hline \multicolumn{5}{|l|}{ Provider J's PSA market share for service $s=37.5 \% .^{12}$} \\
\hline
\end{tabular}

Consider a provider that provides a particular service in four zip codes (see Example 1). The provider receives $\$ 40$ from its Medicare patients in zip code $1, \$ 35$ from those in zip code $2, \$ 15$ from those in zip code 3 , and $\$ 10$ from those in zip code 4 . The provider's PSA consists of zip codes 1 and 2 , since $75 \%$ of its revenue for that service comes from those two zip codes. The provider's market share in its PSA depends on the total Medicare revenue for service $s$ in J's PSA. Example 1 assumes $\$ 100$ of Medicare revenue for each zip code. Therefore, J's PSA market share is $37.5 \%$.

How does this PSA market share compare to the market share for the relevant market? It all depends on what the relevant market is. The relevant market determination depends on numerous factors, such as the willingness of patients to switch providers. To keep the examples simple, I simply assume the relevant market is the PSA plus one or more additional zip codes. In Example 1, the relevant market is assumed to be zip codes 1,2, and 3, so J's market share in the relevant market is $30 \%$. Thus, in Example 1, J's PSA market share is greater than its market share in the relevant market. This suggests that the Proposed Statement's PSA approach overstates market shares in the relevant market and therefore results in a narrower safety zone. Is this result true in general? No.

In fact, J's PSA market share may be greater or less than its RM market share. Example 2 is an example where it is less. The only difference between Examples 1 and 2 is that Medicare revenue for service $s$ to all providers for zip code 3 is 20 instead of 100 . Now J's RM market share is $40.9 \%$, while its PSA market share is $37.5 \%$.

11 The PSA is defined as the fewest number of contiguous zip codes that account for at least $75 \%$ of the provider's revenue. So $75 \%$ of $(40+35+15+10)$ is 75 , which equals the sum of the provider's revenue from zip codes 1 and 2 (i.e., $40+35$ ).

12 Provider J's PSA market share $=100 *(40+35) /(100+100)=37.5 \%$.

13 Id.

${ }^{14}$ Provider J's RM market share $=100 *(40+35+15) /(100+100+100)=30 \%$. 


\begin{tabular}{|c|c|c|c|c|}
\hline \multirow[t]{2}{*}{ Example 2: } & \multicolumn{4}{|c|}{ Zip code } \\
\hline & 1 & 2 & 3 & 4 \\
\hline Provider J's Medicare revenue for service $s$ (dollars) & 40 & 35 & 15 & 10 \\
\hline Medicare revenue for service $s$ to all providers (dollars) & 100 & 100 & 20 & 100 \\
\hline \multicolumn{5}{|l|}{ Provider J's PSA for service $s$ consists of zip codes $1 \& 2.15$} \\
\hline \multicolumn{5}{|l|}{ Provider J's PSA market share for service $s=37.5 \% .{ }^{16}$} \\
\hline
\end{tabular}

Examples 1 and 2 lead to the following proposition:

Proposition 1: A provider's PSA market share may either overstate or understate its market share in its relevant market. 19

The implication of Proposition 1 is that, except in special cases, one cannot conclude that the PSA market share systematically overstates or understates the RM market share.

The PSA Approach also produces market shares that behave in ways that hinder the drawing of inferences about market power. Holding a provider's PSA Medicare revenue constant, increasing its Medicare revenue in an adjacent zip code may cause the provider's PSA market share to fall. In other words, increasing a provider's revenue can cause its PSA market share to decline. This seems counterintuitive because larger providers would be expected to have larger market shares. Yet, under the PSA Approach, this is not necessarily the case because increasing the provider's revenue may expand its PSA. This point is illustrated in Example 3.

\footnotetext{
15 The calculation is the same as in Example 1. Supra note 11.

16 The calculation is the same as in Example 1. Supra note 12.

17 Id.

18 Provider J's RM market share $=100 *(40+35+15) /(100+100+20)=40.9 \%$.

19 There are special cases where the direction of the bias can be determined. For example, if Medicare revenue to all providers for service $s$ is the same for each zip code, then the PSA market share must be greater than or equal to the RM market share due to the way the PSA is constructed (i.e., by summing a non-increasing sequence of numbers). This assumes, however, that the relevant market is composed of the PSA plus one or more additional zip codes.
} 


\begin{tabular}{|c|c|c|c|c|c|c|c|}
\hline \multicolumn{8}{|l|}{ Example 3} \\
\hline \multirow{2}{*}{$\begin{array}{l}\text { Provider J's Medicare revenue for service } s \\
\text { (dollars): }\end{array}$} & \multicolumn{5}{|c|}{ Zip code } & \multirow{2}{*}{$\begin{array}{l}\text { PSA }^{20} \\
\text { (zip } \\
\text { codes) }\end{array}$} & \multirow{2}{*}{$\begin{array}{l}\text { J's PSA } \\
\text { Market } \\
\text { Share }\end{array}$} \\
\hline & 1 & 2 & 3 & 4 & 5 & & \\
\hline Scenario I & 60 & 3 & 2 & 1 & 1 & 1 & $60.0 \%$ \\
\hline Scenario II & 60 & 30 & 2 & 1 & 1 & 1,2 & $45.0 \%$ \\
\hline Scenario III & 60 & 30 & 30 & 1 & 1 & $1,2,3$ & $40.0 \%$ \\
\hline Scenario IV & 60 & 30 & 30 & 30 & 1 & $1,2,3$ & $40.0 \%$ \\
\hline Scenario V & 60 & 30 & 30 & 30 & 30 & $1,2,3,4$ & $37.5 \%$ \\
\hline $\begin{array}{l}\text { Medicare revenue for service } s \text { to all } \\
\text { providers (dollars) (all scenarios) }\end{array}$ & 100 & 100 & 100 & 100 & 100 & & \\
\hline
\end{tabular}

Notice that in each subsequent scenario, Provider J's Medicare revenue from service $s$ is much higher in the adjacent zip code than in the previous scenario. One may suspect that if all zip codes are of equal size (in terms of total Medicare revenue for service $s$ to all providers), then J's market share will increase in each subsequent scenario. In fact, however, the PSA market share does exactly the opposite. It falls. Example 3 leads to the following proposition.

Proposition 2: A provider's PSA market share can decline as it generates more and more revenue in adjacent zip codes.

The Proposed Statement sets forth thresholds for safety zones and mandatory review based on PSA market shares. However, when applied to Provider J in Example 3, some peculiar results emerge.

First, notice that in Scenario I, Provider J appears to be able to attract only those patients who are unwilling to travel even one zip code away to receive service s. In contrast, in Scenario V, Provider J draws exactly the same patients in zip code 1 but also draws a significant number of patients from each of the other zip codes as well. Yet, if any other provider K attempts to form an ACO with Provider J in Scenario I, the ACO will be subject to mandatory review (if K receives any Medicare revenue for service $s$ in zip code 1 since the ACO's market share in J's PSA will exceed $50 \%$ ) or the dominant provider limitation ${ }^{21}$ (if $\mathrm{K}$ does not receive any Medicare revenue for service $s$ in zip code 1 ). Yet, suppose K earns \$2 in Medicare revenue for service $s$ in each of the five zip codes. Then K can form an ACO with J in Scenario V and be subject to neither mandatory review (since the ACO's market

20 For an explanation of how PSAs are determined, see supra note 11.

${ }^{21}$ As set forth in the Proposed Statement, the dominant provider limitation "applies to any ACO that includes a participant with a greater than 50 percent share in its PSA of any service that no other ACO participant provides to patients in that PSA." A 'dominant provider' "must be non-exclusive to the ACO to fall within the safety zone." In addition, "to fall within the safety zone, an ACO with a dominant provider cannot require a commercial payer to contract exclusively with the ACO or otherwise restrict a commercial payer's ability to contract or deal with other ACOs or provider networks." Proposed Statement, supra note 1, p. 21897. 
share in J's PSA will be $39.5 \%$ and thus fall below the $50 \%$ threshold) nor the dominant provider limitation (since K and J provide service $s$ in each other's PSA). ${ }^{22}$ In other words, in at least some cases, the Proposed Statements would screen ACOs involving Provider J in Scenario I as of more antitrust concern than the same ACOs involving Provider J in Scenario V. Yet, it would seem that the latter should raise more antitrust concerns.

The implication is that the Proposed Statement's PSA Approach may flag ACOs involving providers who draw their patients from very small geographic areas as requiring more antitrust scrutiny than providers who draw the same number of patients from those areas but also draw a considerable number of patients from other areas as well. In other words, simple examples suggest that the PSA Approach may screen out for further scrutiny the 'wrong' ACOs.

\section{Comparison of ACO Antitrust Treatment as Set Forth in the Proposed Statement and under the Horizontal Merger Guidelines}

The 2010 Horizontal Merger Guidelines (HMG) describe a merger review process that takes into account both the industry's post-merger concentration, as quantified by the Herfindahl-Hirschman Index (HHI), and the change in concentration due to the merger, as quantified by the difference between the preand post-merger HHIs. Based on these two variables, a merger is classified into one of three categories: (1) unlikely to raise competitive concerns ${ }^{23}$, (2) potentially raises competitive concerns ${ }^{24}$, and (3) presumptively enhances market power. ${ }^{25}$ This will be referred to below as the "HMG Approach."

If the antitrust treatment of ACOs as set forth in the Proposed Statement approximates the antitrust treatment of horizontal mergers under the Horizontal Merger Guidelines, then one may expect the PSA Approach to signal safety zone treatment in those cases where the $H M G$ Approach signals 'unlikely to raise competitive concerns', to signal mandatory review when the HMG Approach signals a presumption of enhancement of market power, and to signal an intermediate level of review when the HMG Approach signals 'potentially raises competitive concerns.' In other words, if potential ACOs are classified by both the PSA Approach and the $H M G$ Approach and recorded on a table such as Table 1, then the entries should all

22 The same is true for K's PSA.

${ }^{23} \mathrm{~A}$ merger is unlikely to raise competitive concerns if either of the following conditions hold: (1) the increase in HHI is less than 100 points, or (2) the postmerger $\mathrm{HHI}$ is below 1500 (i.e., the market remains unconcentrated even after the merger).

${ }^{24} \mathrm{~A}$ merger potentially raises competitive concerns if either of the following conditions hold: (1) the post-merger $\mathrm{HHI}$ is in the 1500-2500 range and the increase in HHI exceeds 100 points, or (2) the post-merger HHI exceeds 2500 and the increase in $\mathrm{HHI}$ is in the 100-200 range.

${ }^{25} \mathrm{~A}$ merger warrants a presumption of enhancement of market power if the postmerger HHI exceeds 2500 and the increase in HHI exceeds 200 points. 
lie on the diagonal if the two approaches generate similar implications. On the other hand, if most of the entries are in the upper right (lower left) then the PSA Approach would appear to be more lax (stringent) in its antitrust treatment than the $H M G$ Approach.

\begin{tabular}{|l|l|l|l|}
\hline Table 1 & \multicolumn{3}{|c|}{ Horizontal Merger Guidelines } \\
\hline ACO Guidelines & $\begin{array}{l}\text { Unlikely to raise } \\
\text { competitive concerns }\end{array}$ & $\begin{array}{l}\text { Potentially raises } \\
\text { competitive concerns }\end{array}$ & $\begin{array}{l}\text { Warrants presumption of } \\
\text { enhancement of market power }\end{array}$ \\
\hline Safety zone & Similar treatment & $\begin{array}{l}\text { ACO Guidelines more } \\
\text { lax }\end{array}$ & ACO Guidelines much more lax \\
\hline Intermediate & $\begin{array}{l}\text { ACO Guidelines more } \\
\text { stringent }\end{array}$ & Similar treatment & ACO Guidelines more lax \\
\hline Mandatory review & $\begin{array}{l}\text { ACO Guidelines much } \\
\text { more stringent }\end{array}$ & $\begin{array}{l}\text { ACO Guidelines more } \\
\text { stringent }\end{array}$ & Similar treatment \\
\hline
\end{tabular}

Do the two approaches yield entries that lie along the diagonal? Once again, a few examples are sufficient to demonstrate that the PSA Approach and $H M G$ Approach produce similar implications in some scenarios, whereas in others the PSA Approach is more lax, and in still others it is more stringent. ${ }^{26}$ To simplify the discussion, I consider only ACOs whose members are not subject to the Proposed Statement's non-exclusivity requirements.

First, consider three providers X, Y, Z who supply service $s$ and that have the same PSA. Suppose their respective PSA market shares for service $s$ are $51 \%, 48.5 \%$, and $0.5 \%$. Now suppose X and Z want to form an ACO. The ACO's market share in the PSA will be $51.5 \%$, and therefore the ACO will be subject to mandatory review. However, using the $H M G$ Approach, the increase in HHI will be only 51 points, and therefore a merger of $\mathrm{X}$ and $\mathrm{Z}$ would be unlikely to raise competitive concerns. ${ }^{27}$ Thus, this is an example where the ACO treatment under the Proposed Statement is stricter than the treatment under the Horizontal Merger Guidelines.

\footnotetext{
${ }^{26}$ For another comparison of the antitrust treatment of ACOs under the Proposed Statement and the Horizontal Merger Guidelines, see Tasneem Chipty, "Competitor Collaborations in Health Care: Understanding the Proposed ACO Antitrust Review Process," CPI Antitrust Chronicle, May 2011 (1). Chipty assumes that the relevant market is the same as the PSA and concludes: "For relatively unconcentrated markets, whether the ACO review process is more stringent than the merger review process depends on how restrictive the non-exclusivity requirement on hospitals and ambulatory surgical centers are to the ACO participants. If they are not binding, the numerical simulations suggest that the ACO review process is no more stringent than the merger review process for relatively unconcentrated markets and less stringent in relatively more concentrated markets." (p. 6)

${ }^{27}$ The change in $\mathrm{HHI}$ is $(51+0.5)^{2}+48.5^{2}-\left(51^{2}+48.5^{2}+0.5^{2}\right)=51$, and thus falls below the 100 point threshold for potentially raising competitive concerns.
} 
At the opposite extreme would be an ACO that qualifies for the Proposed Statement's safety zone, even though under the HMG Approach a merger would warrant the presumption of an enhancement of market power. An example of such an ACO is CDEF in Example 4.

Example 4

\begin{tabular}{|c|c|c|}
\hline Zip code 1 & Zip code 2 & Zip code 3 \\
\hline $\begin{array}{l}\text { Provider(s) located in zip code: } \\
\text { C. }\end{array}$ & $\begin{array}{l}\text { Provider(s) located in zip } \\
\text { code: none. }\end{array}$ & $\begin{array}{l}\text { Provider(s) located in zip code: } \\
\text { D. }\end{array}$ \\
\hline $\begin{array}{l}\text { Medicare revenue for service } s \text {, } \\
\text { by provider (dollars): } \\
\text { A: 72; B: } 5 \text {; C: } 20 \text {; D: } 1 \text {; E: } 1 \text {; F: } 1 .\end{array}$ & $\begin{array}{l}\text { Medicare revenue for service } s \text {, } \\
\text { by provider (dollars): } \\
\text { A: 73; B: 15: C: 5; D: 5; E: 1; F: } \\
\text { 1. }\end{array}$ & $\begin{array}{l}\text { Medicare revenue for service } s \text {, } \\
\text { by provider (dollars): } \\
\text { A: 33; B: 34; C: 1; D: 30; E: 1; F: } \\
\text { 1. }\end{array}$ \\
\hline Zip code 4 & Zip code 5 & Zip code 6 \\
\hline $\begin{array}{l}\text { Provider(s) located in zip code: } \\
\text { none. }\end{array}$ & $\begin{array}{l}\text { Provider(s) located in zip } \\
\text { code: A \& B. }\end{array}$ & $\begin{array}{l}\text { Provider(s) located in zip code: } \\
\text { none. }\end{array}$ \\
\hline $\begin{array}{l}\text { Medicare revenue for service } s \text {, } \\
\text { by provider (dollars): } \\
\text { A: 73; B: } 10 ; \text { C: } 7 \text {; D: } 1 \text {; E: 8; F: } 1 \text {. }\end{array}$ & $\begin{array}{l}\text { Medicare revenue for service } s \text {, } \\
\text { by provider (dollars): } \\
\text { A: } 45 \text {; B: } 45 \text {; C: } 2 \text {; D: } 3 \text {; E: } 3 \text {; F: } \\
2 .\end{array}$ & $\begin{array}{l}\text { Medicare revenue for service } s, \\
\text { by provider (dollars): } \\
\text { A: 10; B: } 73 \text {; C: } 1 \text {; D: 8; E: 1; F: } 7 \text {. }\end{array}$ \\
\hline Zip code 7 & Zip code 8 & Zip code 9 \\
\hline $\begin{array}{l}\text { Provider(s) located in zip code: } \\
\text { E. }\end{array}$ & $\begin{array}{l}\text { Provider(s) located in zip } \\
\text { code: none. }\end{array}$ & $\begin{array}{l}\text { Provider(s) located in zip code: } \\
\text { F. }\end{array}$ \\
\hline $\begin{array}{l}\text { Medicare revenue for service } s \text {, } \\
\text { by provider (dollars): } \\
\text { A: 34; B: 33; C: 1; D: 1; E: 30; F: } \\
\text { 1. }\end{array}$ & $\begin{array}{l}\text { Medicare revenue for service } s \text {, } \\
\text { by provider (dollars): } \\
\text { A: 15; B: } 73 \text {; C: } 1 \text {; D: } 1 \text {; E: } 5 \text {; F: } \\
\text { 5. }\end{array}$ & $\begin{array}{l}\text { Medicare revenue for service } s, \\
\text { by provider (dollars): } \\
\text { A: 5; B: 72; C: 1; D: 1; E: 1; F: } 20 \text {. }\end{array}$ \\
\hline
\end{tabular}

Suppose Providers A, B, C, D, E, and F provide service $s$ in nine zip codes in the Medicare amounts listed. ${ }^{28}$ Notice that each provider generates its greatest revenue near its location. Providers $A$ and $B$ generate substantial revenue from nearby zip codes as well, while Providers C, D, E, and F are basically regional providers whose revenue declines very sharply as one moves away from their home territories.

28 By conducting calculations as described in footnote 11 , A's PSA can be determined to be comprised of zip codes 1, 2, 4, 5, and 7; B's PSA consists of zip codes 2, 5, 6, 8, and 9; C's PSA consists of zip codes 1, 2, and 4; D's PSA consists of zip codes 2, 3, and 6; E's PSA consists of zip codes 4, 7, and 8; and F's PSA consists of zip codes 6, 8, and 9. 
Table 2 summarizes the antitrust treatment of all 15 possible two-provider ACOs. ${ }^{29}$ Note that all two-provider ACOs fall along the diagonal. In other words, the two-provider ACOs that qualify for the Proposed Statement's safety zone also would be deemed unlikely to raise competitive concerns under the HMG Approach, whereas the ones that require mandatory review under the Proposed Statement are also the ones that the $H M G$ Approach identifies as warranting the presumption that a merger would enhance market power. Notice that all the two-provider ACOs that do not involve Providers A or B qualify for the Proposed Statement's safety zone.

Table 2: Antitrust Treatment of ACOs Formed by Providers in Example 4
\begin{tabular}{l|l|l|l|}
\multicolumn{3}{|c|}{ Horizontal Merger Guidelines } \\
\hline ACO Guidelines & $\begin{array}{l}\text { Unlikely to raise } \\
\text { competitive concerns }\end{array}$ & $\begin{array}{l}\text { Potentially raises } \\
\text { competitive concerns }\end{array}$ & $\begin{array}{l}\text { Warrants presumption of } \\
\text { enhancement of market power }\end{array}$ \\
\hline Safety zone & CD,CE,CF,DE,DF,EF & & CDEF \\
\hline Intermediate & & & AB,AC,AD,AE,AF,BC,BD,BE,BF \\
\hline Mandatory review & & & \\
\hline
\end{tabular}

On the other hand, an ACO formed with all four regional providers C, D, E, and F also would qualify for the Proposed Statement's safety zone since that ACO's market share in each of the four PSAs (one for each ACO participant) would be less than $30 \%$. However, under the HMG Approach, the post-ACO PSAs would be highly concentrated and two would have HHI increases of more than 200 points, thereby classifying ACO CDEF as warranting the presumption of an enhancement in market power.

Example 5 illustrates a scenario in which six providers, A through $\mathrm{F}$, provide service $s$ in nine zip codes, and two other providers, $\mathrm{G}$ and $\mathrm{H}$, also provide the service in the nine zip codes but operate in others as well (and therefore the PSAs of $\mathrm{G}$ and $\mathrm{H}$ are left unspecified). ${ }^{30}$ The PSA of each provider A through $\mathrm{F}$ has a pre-ACO HHI of less than 1500, and thus is unconcentrated. ${ }^{31}$ However, any two-provider ACO comprised of providers A through F results in a post-ACO HHI of more than 1500 (but less than 2500) so that the post-ACO market is relatively concentrated.

29 The HHIs are calculated assuming that each provider's PSA is the relevant market. However, the qualitative results do not change if, instead, the relevant market for all providers is assumed to consist of all nine zip codes.

30 Since the PSAs of providers $\mathrm{G}$ and $\mathrm{H}$ are left unspecified, the example does not consider ACOs that involve $\mathrm{G}$ or $\mathrm{H}$.

31 This conclusion also holds if the relevant market for Providers A through $\mathrm{F}$ is assumed to be comprised of all nine zip codes. 
Notice that the PSAs in Example 5 include more zip codes than the PSAs in Example $4 .{ }^{32}$

Example 5

\begin{tabular}{|c|c|c|}
\hline Zip code 1 & Zip code 2 & Zip code 3 \\
\hline $\begin{array}{l}\text { Provider(s) located in zip code: } \\
\text { C. }\end{array}$ & $\begin{array}{l}\text { Provider(s) located in zip } \\
\text { code: none. }\end{array}$ & $\begin{array}{l}\text { Provider(s) located in zip code: } \\
\text { D. }\end{array}$ \\
\hline $\begin{array}{l}\text { Medicare revenue for service } s \text {, } \\
\text { by provider (dollars): } \\
\text { A: 18; B: } 14 ; \text { C: 18; D: 14; E: 15; } \\
\text { F: 9; G: 6; H: } 6 .\end{array}$ & $\begin{array}{l}\text { Medicare revenue for service } s \text {, } \\
\text { by provider (dollars): } \\
\text { A: 20; B: } 19: \text { C: } 16 \text {; D: } 16 \text {; }: 9 \text {; } \\
\text { F: 8; G: } 6 \text {; H: } 6 .\end{array}$ & $\begin{array}{l}\text { Medicare revenue for service } s \text {, } \\
\text { by provider (dollars): } \\
\text { A: 17; B: } 17 \text {; C: 16; D: 18; E: 9; F: } \\
\text { 11; G: } 6 \text {; H: } 6 .\end{array}$ \\
\hline Zip code 4 & Zip code 5 & Zip code 6 \\
\hline $\begin{array}{l}\text { Provider(s) located in zip code: } \\
\text { none. }\end{array}$ & $\begin{array}{l}\text { Provider(s) located in zip } \\
\text { code: A \& B. }\end{array}$ & $\begin{array}{l}\text { Provider(s) located in zip code: } \\
\text { none. }\end{array}$ \\
\hline $\begin{array}{l}\text { Medicare revenue for service } s \text {, } \\
\text { by provider (dollars): } \\
\text { A: 19; B: 16; C: 17; D: 9; E: 18; F: } \\
\text { 9; G: 6; H: } 6 \text {. }\end{array}$ & $\begin{array}{l}\text { Medicare revenue for service } s \text {, } \\
\text { by provider (dollars): } \\
\text { A: } 24 ; \text { B: } 24 \text {; C: } 10 \text {; D: } 10 \text {; E: } 10 \text {; } \\
\text { F: } 10 \text {; G: } 6 \text {; H: } 6 .\end{array}$ & $\begin{array}{l}\text { Medicare revenue for service } s \text {, } \\
\text { by provider (dollars): } \\
\text { A: 16; B: } 18 ; \text { C: } 15 ; \text { D: 16; E: 7; F: } \\
\text { 16; G: 6; H: } 6 .\end{array}$ \\
\hline Zip code 7 & Zip code 8 & Zip code 9 \\
\hline $\begin{array}{l}\text { Provider(s) located in zip code: } \\
\text { E. }\end{array}$ & $\begin{array}{l}\text { Provider(s) located in zip } \\
\text { code: none. }\end{array}$ & $\begin{array}{l}\text { Provider(s) located in zip code: } \\
\text { F. }\end{array}$ \\
\hline $\begin{array}{l}\text { Medicare revenue for service } s \text {, } \\
\text { by provider (dollars): } \\
\text { A: 18; B: } 18 \text {; C: } 14 \text {; D: 6; E: 18; F: } \\
\text { 14; G: 6; H: } 6 \text {. }\end{array}$ & $\begin{array}{l}\text { Medicare revenue for service } s \text {, } \\
\text { by provider (dollars): } \\
\text { A: } 15 ; \text { B: } 19 \text {; C: } 13 \text {; D: } 8 \text {; E: } 16 \text {; } \\
\text { F: } 17 ; \text { G: } 6 \text {; H: } 6 .\end{array}$ & $\begin{array}{l}\text { Medicare revenue for service } s \text {, } \\
\text { by provider (dollars): } \\
\text { A: } 14 ; \text { B: } 18 ; \text { C: } 12 ; \text { D: } 13 \text {; E: } 13 \text {; } \\
\text { F: } 18 ; \text { G: } 6 ; \mathrm{H}: 6 .\end{array}$ \\
\hline
\end{tabular}

Table 3 summarizes the antitrust treatment of ACOs formed by the providers in Example 5. The increase in HHI in each of the ACO participants' PSA exceeds 100 points, so the ACO potentially raises competitive concerns under the $H M G$ Approach. ${ }^{33}$ On the other hand, the six two-provider ACOs that do not include providers A or B all qualify for the Proposed Statement's safety zone, and all the ones that do include A or B do not (but they also do not meet the mandatory review requirement). Therefore, Example 5 illustrates a scenario where the PSA Approach

32 A's PSA consists of zip codes 1, 2, 3, 4, 5, 6, and 7; B's PSA consists of zip codes 2, 3, 5, 6, 7, 8, and 9; C's PSA consists of zip codes 1, 2, 3, 4, 6, 7, and 8; D's PSA consists of zip codes 1, 2, 3, 5, 6, and 9; E's PSA consists of zip codes 1, 4, 5, 7, 8, and 9; and F's PSA consists of zip codes 3, 5, 6, 7, 8, and 9.

33 This conclusion also holds if the relevant market for Providers A through $\mathrm{F}$ is assumed to be comprised of all nine zip codes. 
yields a more refined categorization of the anti-competitive potential of certain potential ACOs relative to the $H M G$ Approach.

\begin{tabular}{|l|l|l|l|}
\hline \multicolumn{1}{|l|}{ Table 3: Antitrust Treatment of ACOs Formed by Providers in Example 5 } \\
& \multicolumn{3}{|c|}{ Horizontal Merger Guidelines } \\
\hline & $\begin{array}{l}\text { Unlikely to raise } \\
\text { competitive } \\
\text { concerns }\end{array}$ & $\begin{array}{l}\text { Potentially raises } \\
\text { competitive concerns }\end{array}$ & $\begin{array}{l}\text { Warrants presumption of } \\
\text { enhancement of market } \\
\text { power }\end{array}$ \\
\hline Safety zone & CD,CE,CF,DE,DF,EF & \\
\hline Intermediate & & AB,AC,AD,AE,AF,BC,BD,BE,BF & \\
\hline $\begin{array}{l}\text { Mandatory } \\
\text { review }\end{array}$ & & \\
\hline
\end{tabular}

\section{Conclusion}

The Proposed Statement replaces the familiar, but often contentious, "relevant market" with the "primary service area." Yet, the PSA, according to the Proposed Statement, "does not constitute a relevant antitrust geographic market" but "nonetheless provides a useful tool for evaluating potential competitive effects." The PSA is indeed useful in the sense that, given the same data, everyone should be able to agree on the PSA of each provider for each service. The same probably could not be said of each provider's relevant market.

Nonetheless, the 1996 Statements, the 2000 Collaborations, and the 2010 Horizontal Merger Guidelines set forth safety zones based on the relevant market, not PSAs. The safety zones set forth in the 1996 and 2000 documents are based on market share thresholds, as is the one set forth in the Proposed Statement. In comparing the implications of these different approaches, the central question is how closely the PSA approximates the relevant market. Proposition 1 says that a provider's PSA market share may be either higher or lower than its market share in its relevant market. Proposition 2 says that a provider's PSA market share may decline as it generates more and more revenue from adjacent zip codes. These two propositions suggest that drawing inferences from PSA markets shares about market shares in relevant markets, and about competitive effects more generally, is problematic at best.

The safety zone set forth in the Horizontal Merger Guidelines, in contrast, is based on post-merger HHI and the change in HHI. Not surprisingly, since the safety zone in the Proposed Statement does not depend on market concentration or the change in concentration from ACO formation, the two approaches can give very different indications of the anticompetitive potential of the same ACO. Two scenarios where the PSA and $H M G$ approaches may be expected to yield very different competitive assessments are (1) an ACO formed between a very large 
provider and a very small one so that the Proposed Statement requires mandatory review because the ACO's PSA market share exceeds 50\% whereas the Horizontal Merger Guidelines suggest it is unlikely to raise competitive concerns because the increase in HHI will be small (i.e., less than 100 points) and (2) an ACO formed by geographically-dispersed strong local providers that generate little revenue outside their immediate location so that the ACO's market share in each provider's PSA falls below the $30 \%$ safety zone threshold even though the increase in concentration from the ACO's formation is sufficiently large given the high post-ACO concentration to warrant the presumption of an enhancement of market power.

In summary, sometimes PSA market shares provide meaningful information about competitive effects that is consistent with other approaches based on the relevant market; sometimes they do not. The problem is knowing when they do and when they don't. Maybe the PSA approach captures important information that the other approaches miss. Without a better understanding of the answer to these issues, however, it seems a bit premature to describe the PSA, as the Proposed Statement does, as "a useful tool for evaluating potential competitive effects." 